\title{
Air exchange calculation in traditional buildings of orthodox churches in Russia
}

\author{
Alexey Kochev ${ }^{1}$, Mikhail Sokolov ${ }^{1}$, Kirill Lushin ${ }^{2 *}$ \\ ${ }^{1}$ Nizhniy Novgorod State University of Architecture and Civil Engineering, 603950, Russia, Nizhniy \\ Novgorod, Ilyinskaya St. h. 65 \\ ${ }^{2}$ Moscow State University of Civil Engineering, Yaroslavskoe shosse, 26, Moscow, 129337, Russia
}

\begin{abstract}
The paper devoted to indoor air quality providing in orthodox churches in Russia. Using the results of theoretical and experimental research made some practical recommendations for design and installation of ventilation systems in orthodox churches. Significant part of research deals with air and constructions humidity controls by reverse osmosis. It is reaffirmed that the rate of dehumidification is directly connected with the air exchange rates and operation of space heating devises in premises. It is very common to use natural ventilation in old churches. It is very easy to install and maintain, but still this way of indoor air conditions providing is absolutely not sustainable. And to avoid the leak of ventilation efficiency for different rooms it is recommended to provide mechanical supply and exhaust ventilation. Another significant issue for providing rapid wall dehumidification is properly operating space heating. It is noted that heating should be combined with an action of ventilation and electroosmotic drying.
\end{abstract}

\section{Introduction}

Russia is a very touristic country with permanently rising tourists flow in all year around. The most points of interest are connected with mid ages Russian history. And the significant part of historical heritage is traditions, people and facilities of Orthodox Christian Russian church. Physical condition and sustainable maintenance of churches is up to date issue for old Russian cities and places. These days significant investments and attention attracted into retrofitting of XVIII - XX centuries historically valuable facilities. Some of them are still in unsatisfactory conditions and found to be at risk of loss. The most damaged part of typical heritage facility is ventilation and heat supply systems. Abnormal maintenance and decreased operation efficiency lead to emerging sick building syndrome with negative influence on indoor air [1] quality and constructions conditions.

The traditional approach to wall waterproof isolation is not always possible for technical reasons. Sometimes access to the underground part of the building envelope is limited for geological limits. And sometimes because of the building foundation type and construction. It is almost always unacceptable to use waterproofing on the inside part of the structure. Since

* Corresponding author: LushinKI@mgsu.ru 
this leads to the loss of the historical appearance of all building parts and the destruction of ancient frescoes and images. Therefore, the key task for us in these cases is to find special innovative methods for premises dehumidification and protection of walls from moisture.

\section{Method}

As the main solution, we proposed to make the wall body dehumidification by the electroosmotic drying method. The technique is based on evaporating of moisture inside-out of a wall under the action of artificially made electric and magnetic fields. Moister movement should be induced in the opposite to the action of capillary forces direction. The moisture mass flow could be estimated by next way:

$$
m_{e}=\frac{k_{e^{*} \Delta \varphi * F * \tau * \rho_{0}}}{l}
$$

here $\mathrm{k}_{\mathrm{e}}-$ is an electroosmotic coefficient and could be found using the next string:

$$
k_{e}=\frac{\varepsilon_{0} * \varepsilon * \xi}{\mu}
$$

In above $\mathrm{F}, \mathrm{m}^{2}$ is an estimating area; $1, \mathrm{~m}$ - capillary length; $\tau$, sec. - acting time; $\rho_{0}, \mathrm{~kg} / \mathrm{m}^{3}$ - fluid density; $\varepsilon$ - relative dielectric constant of the wall body; $\varepsilon_{0}$ - electrical constant; $\zeta, \mathrm{V}$ electrokinetic potential; $\mu, \mathrm{kg} / \mathrm{m} \mathrm{sec}$ - fluid dynamic viscosity coefficient; $\Delta \varphi, \mathrm{V}$ - applied electrical potential difference.

Moisture movement velocity in this case could represented as:

$$
w=\frac{\varepsilon_{0} \cdot \varepsilon \cdot \Delta \varphi \cdot \zeta}{\eta \cdot l},
$$

where the $\eta, \mathrm{kg} / \mathrm{m} \mathrm{sec}$ - moisture viscosity coefficient.

There are significant differences between theoretical approach and practical cases in estimating moisture movement in wall or foundation body. In real conditions electroosmotic mass transfer depends on many different circumstances. Such as form and shape, temperature, wall properties and etc. These differences and conditions must be taken into consideration. Reliable way for that is to use correction factor:

$$
K_{c h}=2 \cdot 10^{-5} * U^{2}+0.001 * \mathrm{U}+0.0557
$$

Here $U, \mathrm{~V}-$ is applied electrical voltage.

$\mathrm{K}_{\mathrm{ch}}$ differs for variable types of walls and foundations. And in (4) it is proposed for brick wall with through rods. This is one of the most common case for XVIII century and earlier. For another types of constructions $\mathrm{K}_{\mathrm{ch}}$ should be refined according to moisture transfer properties of exact wall type.

The basics of electroosmotic drainage proposed in late 1960 by O.Fridman [2]. The main actions during the preparing for acting is to find the immersion depth and distance between rods and voltage to put on it. The next point is to restore or rebuild exhaust ventilation system. 
As a result of electroosmotic dehumidification, moisture from the body of the wall is filtered to the surface and evaporates into the volume of the air in the room. Adequately functioning exhaust ventilation completes the process by removing the humidified air outside the room. Determination of the extract air flow is also a particularly important task. But according to O. Fridman it is obvious to use the (5) for that:

$$
L=\frac{1000 * m_{\mathrm{H}_{2} \mathrm{O}}}{\left(d_{e x}-d_{i n}\right) \rho_{\mathrm{H}_{2} \mathrm{O}} * \tau}
$$

Here $m_{\mathrm{H}_{2} \mathrm{O}}, \mathrm{kg}$ - amount of water evaporated from wall body; $d_{\text {ex }}, \mathrm{g} / \mathrm{kg}-$ exhaust air moisture content; $d_{i n}, \mathrm{~g} / \mathrm{kg}$ - supply air moisture content; $\rho_{\mathrm{H}_{2} \mathrm{O}}, \mathrm{kg} / \mathrm{m} 3$ - fluid density; $\tau$, hour - time.

It should be noticed that this is not the only and the single one way to achieve dry and sustainable indoor space and constructions conditions. Ventilation and space heating is mandatory for both protecting a building and providing indoor air quality.

\section{Results}

It is quite common [3] using natural ventilation for supply air inlet (5) in old churches. Natural ventilation is easy to install and maintain, but still it is not stable in action. And to avoid differences in ventilation efficiency for different parts of facility it is better to provide mechanical supply and exhaust ventilation. At least for the drying periods. In cases with different ventilation efficiency with wide range of ventilation air flow time for evaporating moisture will be variable. This is indicated on Fig.1.

Indoor air conditions are dependent of current facility load caused by number of visitors inside the church at the moment [4], space heating energy supply and even number of enlightened candles. As for space heating [4], there are only four cases of heater and window mutual placement. First one, if at once heater and window exist in on room. The second only window, then - only heater. And ultimately no heater and no window. Al that cases make different input in natural ventilation operating and thermal and moisture conditions in a room.

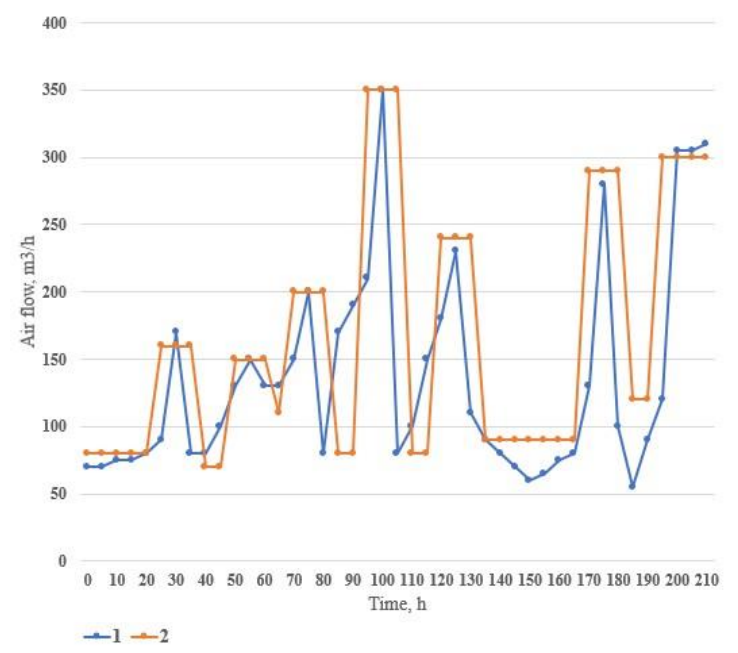

Fig. 1. The relationship between air flow and dehumidification rate (time in hours) for room with clay bricks with pins at a voltage of 30 Volt. 1- theoretical calculation; 2 - experimental data. 
The research, made in Vozneseniya gospodnya church placed on Ilinskaya Street in Nizhny Novgorod, in some special points on wall surface were collected the temperature data. As a main tool was used Raytek Raynger ST20 infrared thermometer. Indoor air movement was checked by TTM-2/1-06-2A thermal anemometer. For walls without windows, the air temperature reached value up to $18,6^{\circ} \mathrm{C}$. Air speed was estimated in between 0,05 and $0,2 \mathrm{~m} / \mathrm{s}$. Over heater and near the window the air temperature was higher, up to $20.1{ }^{\circ} \mathrm{C}$ and the air flow speed reached $0,32 \mathrm{~m} / \mathrm{s}$. [1] In the case of a stand-alone without window heating device, the air temperature was $21.5^{\circ} \mathrm{C}$ and air speed reached $0.37 \mathrm{~m} / \mathrm{s}$. All collected data indicated on Fig.2
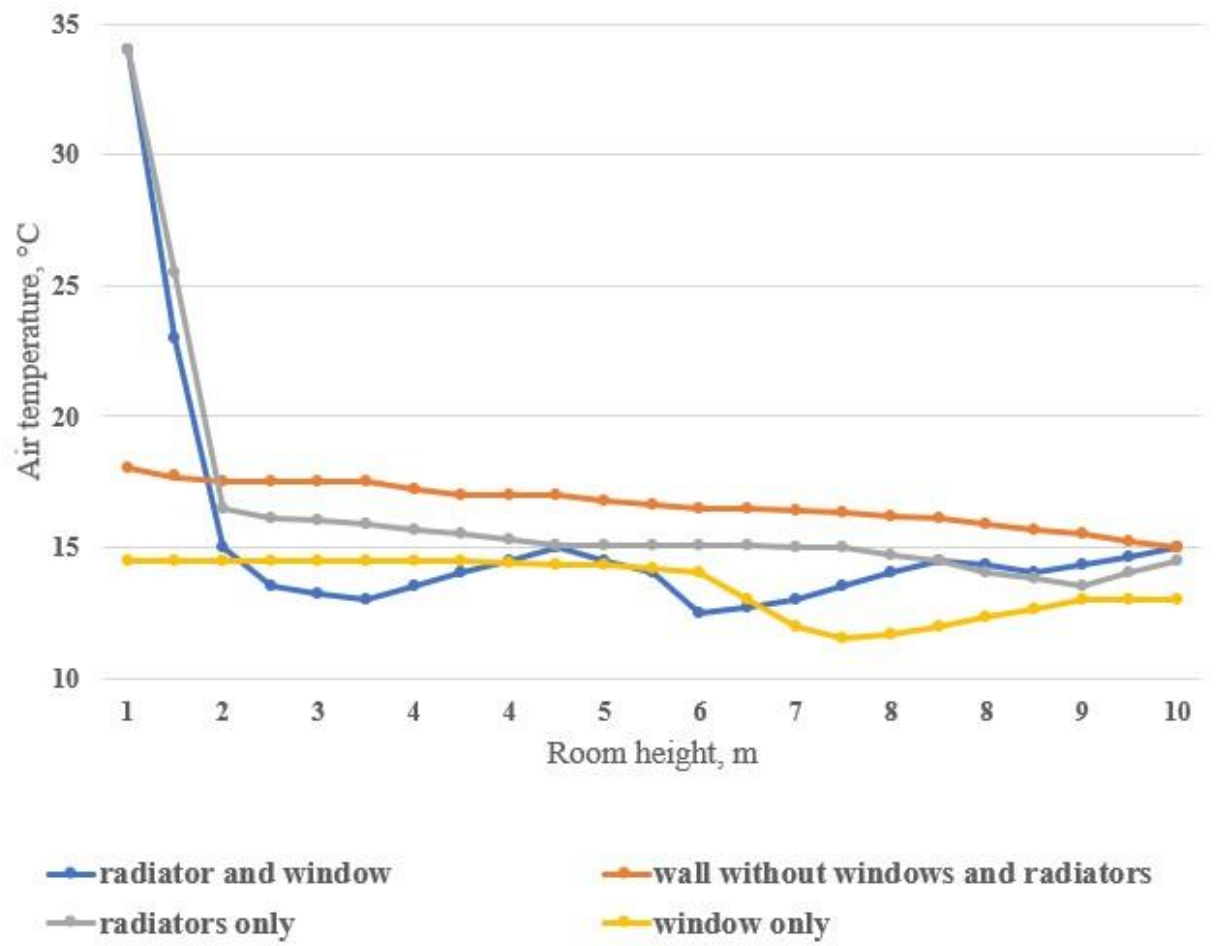

Fig. 2. The wall surface temperature for different cases of mutual placement of heaters and windows in the rooms with different height ceilings.

Natural ventilation efficiency depends not only on features of premises, heaters or number of windows. It is much more complex. Absolutely mandatory is taking into consideration indoor and outside aerodynamics of a building. Especially in cases with natural ventilation only. If there are no mechanically provided air flows in ventilation channels. Research on building aerodynamics consists of different parts. The first one is computer aided modelling and the next - physical modelling (fig.3). The results and data collected on both parts must be compared. And both models could be tuned to get more repeatable and reliable results [3]. 


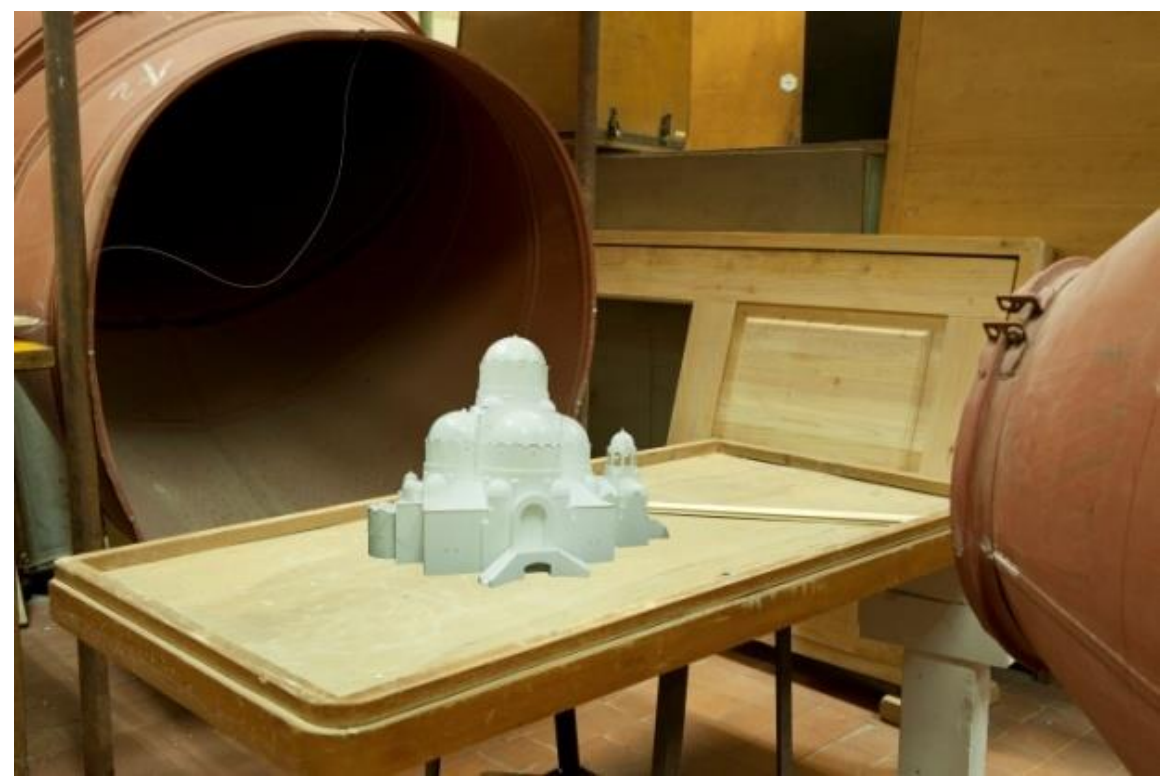

Fig. 3. The research of external aerodynamics on a physical model of real existing Cathedral.

The research in aerodinamics using physical modeling is a reliable way to get data about outer conditions influencing on natural and mechanical ventilation operation properties. It is very common to combine and add a data collected on the model to complex dataset of a research.

\section{Discussion}

It is not the same as for other civil buildings, where the typical gap from the heater to the windowsill is not more then $200 \mathrm{~mm}$. Typical for churches is to rise it from 0,5 to $1 \mathrm{~m}$ or even more. Excessive heat is also formed both from visitors and burning candles. This unsafe tradition put in danger ancient frescoes and icons. The main factor of peril is smoke that leaves a trail of ash on all surfaces. The upward convective air flow from the heat source moves the candles soot to the upper space. This leads to damaging of frescoes or icons placed as usual on the wall surface. In different parts of a world with keeping orthodox traditions such as Montenegro and Greece there are separate spaces for icons and for enlighten candles. And it is much more better for saving ancient church artefacts in better conditions. But at the same time this tight heat flow from different sources is good for supporting natural ventilation air flow. And therefore it is good for fastest dehumidifying both walls and inner spaces of premises. From the other side we get the similar conditions for heating devices as for civil buildings, especially since the placing of radiators in Orthodox churches is almost always open. The values of speed and temperature fields over heating devices in Orthodox churches were determined experimentally.

As a result of this research it was developed the method for design and calculating natural ventilation. There are four steps to pass:

1) To find the moisture flow from wall body into inner space of controlling premises.

2) Calculate a heat flow from heating system, visitors, candles and other sources

3) Check the available performance of aeration using windows and other open ways.

4) Check the ability of air flow from point 3 to transport all calculated moisture from point 1 . If not, change size, number, height of windows from 3 and repeat the check from step 2 . 
The heat balance inside of a building estimating for three parts of the year: cold, transitional and warm. [5-7]. The most common is to design aeration with the combined complex action of heat and wind. Taking into consideration the architectural and design features of orthodox churches [7], it is necessary to arrange sufficient tests for air movement outside the facility [8]. During these tests could be indicated and proved the values aerodynamic coefficients. The main points for air movement research is places near windows and air inlets and outlets. It should be noticed that aerodynamic coefficient does not depend on climatic conditions. For the same purpose, aerodynamic coefficients are measured at each characteristic point where supply and exhaust openings could be located [3]. Such an approach makes possible to choose the most effective design solution for the location and position of natural ventilation system parts. It will depend on the prevailing wind directions, outdoor temperature and other climate features and season of a year.

\section{Conclusions}

When designing natural ventilation systems, it is necessary to consider factors such as architectural and structural features of orthodox churches $[9,10,11]$, the power of heating systems $[12,13,14]$, heat generation from visitors and inhabitants, candles and church lamps [15]. The thermal and air humidity conditions of ancient time facilities could be the issue of saving the unique interiors and the whole constructions $[1,3,5]$. And for sure for space heating capacity and heat consumption of historical buildings of different type $[4,15]$. The developed methods for the rational combination of electro osmotic drainage of walls and controlled air exchange can reduce the drainage time of high moisture building envelopes to sufficient moisture within 4-18 months and preserve historical layers and murals. Selfregulation of aeration air exchange $[16,17]$ creates permissible meteorological [18] conditions in temples. And this will ensure the safety of historical and architectural monuments for decades. If considering a winter as a main period of destructive influence of indoor air conditions on walls and other massive elements it could be missed the significant role of a warm part of a year. During the summer [19] some negative moister and leak of ventilation consequences could be mitigated. And much more rapidly than ever in other terms. And for further research could be taken some topics in a field of energy efficiency and estimation of walls and indoor space drying rates.

\section{References}

1. Korniyenko S. Advanced Hygrothermal Performance of Building Component at Reconstruction of S. Radonezhskiy Temple in Volgograd // MATEC Web Conf. / ed. Murgul V. 2016. Vol. 53. P. 01003.

2. Fridman, O. M. Electro-osmotic method of eliminating the dampness of the walls of buildings / O. M. Fridman; Stroyizdat, 1971. - 95 p.

3. Kochev, A., Sokolov, M., Lushin, K. Natural ventilation and aerodynamics of orthodox churches. // IOP Conference Series: Materials Science and Engineering, 2020, 869(4), 042022 .

4. ABOK Standard-2-2004. Orthodox churches. Heating, ventilation and air conditioning. - шт effect from 2004-06-09. - M.: ABOK, 2004 .- 14 p.

5. Kochev, A., Lushin, K., Sokolov, M., Kocheva, E., Kocheva, M. Ways of heat losses reduction in the structural elements of unique buildings. // MATEC Web of Conferences. Volume 144, 9 January 2018, 04022. 
6. Busahin A.V. Main features of HVAC in ortodox churches. // AVOK Ventilyaciya, otoplenie, kondicionirovanie vozduha, teplosnabzhenie i stroitel'naya teplofizika. 2017. Vol. 2. P. 44-47.

7. S.V. Korniyenko, Construction of Unique Buildings and Structures, 5 (20), 39-53 (2014)

8. Nappa M. et al. Adaptive ventilation for climate control in a medieval church in cold climate // Int. J. Vent. 2016. Vol. 15, № 1.

9. Tone Marie Olstad, Anne Apalnes Ørnhøi, Nina Kjølsen Jernæs, Lavinia de Ferri, Ashley Freeman, Chiara Bertolin. Preservation of Distemper Painting: Indoor Monitoring Tools for Risk Assessment and Decision Making in Kvernes Stave Church. // Special Issue "World Heritage and Climate Change: Impacts and Adaptation". Climate 2020, \#8(2), 33

10. Goded, T., Lewis, A. \& Stirling, M. Seismic vulnerability scenarios of Unreinforced Masonry churches in New Zealand. // Bull Earthquake Eng 16, 3957-3999 (2018). https://doi.org/10.1007/s10518-018-0351-7

11. Samarin O., Lushin K., Paulauskaite S., Valancius K. Influence of the outside climate parameters on the selection of the optimum combination of the energy saving measures. // Technological and Economic Development of Economy. 2009. V. 15. N 3. p. 480-489.

12. Gagarin V.., Kozlov V.., Lushin K.. Calculation of the velocity of air in the air gap facade systems, where natural ventilation // Int. J. Appl. Eng. Res. 2015. Vol. 10, № 23. P. 43438-43441.

13. Tihana J., Odineca T., Borodinecs A., Gendelis S., Jakovics A., Optimal properties of external building envelope for minimization of over heating. // IOP Conference Series: Earth and Environmental Science. 2019 vol: 390 (1)

14. Parfentieva, N., Samarin, O., Lushin, K., Paulauskaite, S. The numerical and analytical methods of calculations of two-dimensional temperature fields in dangerous members of building enclosures.(2008) 7th International Conference on Environmental Engineering, ICEE 2008 - Conference Proceedings, pp. 854-858.

15. Valentino Sangiorgio, Giuseppina Uva \& Jose M. Adam (2020) Integrated Seismic Vulnerability Assessment of Historical Masonry Churches Including Architectural and Artistic Assets Based on Macro-element Approach, International Journal of Architectural Heritage, DOI: 10.1080/15583058.2019.1709916

16. Shchukina T.V. et al. Influence on the Microclimate of the Number of People at Different Occupancy Temples // IOP Conference Series: Materials Science and Engineering. 2020. Vol. 753, № 5.

17. Zubarev K., Gagarin V. Determining the coefficient of mineral wool vapor permeability in vertical position // Advances in Intelligent Systems and Computing. 2021. Vol. 1259 AISC. 593-600 p.

18. Sevryugina N. et al. The concept of sustainability management of the ecosystem of cities and small settlements // IOP Conference Series: Materials Science and Engineering. 2020. Vol. 944, № 1.

19. Malyavina E., Frolova A. The influence of the solar radiation heat input into the room on the level of energy-efficient thermal protection of the building // E3S Web of Conferences. 2019. Vol. 97. 